\title{
Inhaltsverzeichnis zu Band I
}

1. Beispiele von Automaten

1.1. Der Wechselautomat . . . . . . . . . . . . . . . 7

1.2. Die Mausefalle . . . . . . . . . . . . . . . . . . . 8

1.3. Flip-Flop-Elemente . . . . . . . . . . . . . . . . 12

1.4. Die Uhr . . . . . . . . . . . . . . . . . . . . . 15

1.5. Aufstieg und Abstieg . . . . . . . . . . . . . . . 17

1.6. Elektronenübergänge . . . . . . . . . . . . . . . 19

1.7. Frage und Antwort . . . . . . . . . . . . . . . . 21

2. Abstrakte Automaten

2.1. Definitionen . . . . . . . . . . . . . . . . . . 21

2.2. Darstellungen endlicher abstrakter Automaten . . . 25

2.3. Isomorphie und Homomorphie . . . . . . . . . . . 32

2.4. Äquivalenz und Reduktion . . . . . . . . . . . . . . . 43

2.5. Ereigniskalkül . . . . . . . . . . . . . . . . . . 56

2.6. Realisierungen durch Flip-Flop-Elemente . . . . . . 61

2.7. Realisierungen durch formale Neuronen . . . . . . . 71

2.8. Lernsystem und Lernproze $B$. . . . . . . . . . . . 79

Anhang I

1. Mengen . . . . . . . . . . . . . . . . . . . . . . 92

2. Boolesche Funktionen . . . . . . . . . . . . . 94

Literatur. . . . . . . . . . . . . . . . . . . . . . . . . 99

Sachverzeichnis . . . . . . . . . . . . . 101 